\title{
Genetic Dissection Defines the Roles of Elsinochrome Phytotoxin for Fungal Pathogenesis and Conidiation of the Citrus Pathogen Elsinoë fawcettii
}

\author{
Hui-Ling Liao and Kuang-Ren Chung \\ Citrus Research and Education Center, and Department of Plant Pathology, Institute of Food and Agricultural Sciences (IFAS), \\ University of Florida, 700 Experiment Station Rd., Lake Alfred 33850, U.S.A.
}

Submitted 25 October 2007. Accepted 6 December 2007.

\begin{abstract}
Elsinochrome pigments produced by many phytopathogenic Elsinö̈ spp. are nonhost-selective toxins which react with oxygen molecules after light activation to produce highly toxic reactive oxygen species. The structures and chemical properties of four derivatives are well known. However, the biological roles of elsinochromes in fungal pathogenesis are poorly understood. Many isolates of Elsinö fawcettii causing citrus scab are able to produce elsinochromes under axenic conditions. In this article, we report the cloning, expression, and functional characterization of the polyketide synthase-encoding gene, EfPKS1, which we show is required for the production of elsinochromes and fungal pathogenesis. Targeted disruption of EfPKS1 in E. fawcettii completely abrogated elsinochrome production, drastically reduced conidiation, and significantly decreased lesion formation on rough lemon leaves. All mutant phenotypes were restored to the wild type in fungal strains expressing a functional copy of EfPKS1. Accumulation of the EfPKS1 transcript and elsinochromes by a wild-type strain appears to be coordinately regulated by light, nutrients, and $\mathrm{pH}$. The results indicate that the product of EfPKS1 is involved in the biosynthesis of elsinochromes via a fungal polyketide pathway, and that elsinochromes play an important role in fungal pathogenesis.
\end{abstract}

Additional keywords: perylenequinone, photosensitizers, split marker, targeted gene disruption

Many phytopathogenic fungi produce perylenequinone pigments, which are light-activated and nonhost-selective phytotoxins (Daub et al. 2005). These compounds include alteichin, altertoxin, alterlosin, and stemphyltoxin produced by Alternaria spp. (Davis and Stack 1991; Stack et al. 1986) and Stemphylium botryosum (Davis and Stack 1991); cercosporin and isocercosporin produced by many Cercospora spp. (Daub et al. 2005), as well as Scolicotrichum graminis (Tabuchi et al. 1994) and Stagonospora convolvuli (Ahonsi et al. 2005); elsinochromes produced by many Elsinoë and Sphaceloma spp. (Liao and Chung 2008; Weiss et al. 1987) as well as S. convolvuli (Ahonsi et al. 2005); hypomycin A produced by Hypomyces spp. (Liu et al. 2001); hypocrellin produced by the bamboo pathogen, Hypocrella bambusae (Weiss et al. 1987); shiraiachromes produced by another bamboo pathogen, Shiraia bambusicola (Wu et al. 1989); and phleichrome, calphostin C,

Corresponding author: K.-R. Chung; Telephone: 1 + (863) 956-1151 ext. 1369; Fax: 1 + (863) 956-4631; E-mail krchung@ufl.edu cladochrome, and ent-isophleichrome produced by Cladosporium spp. (Arnone et al. 1988; Weiss et al. 1987).

Among all phytotoxins identified, perylenequinone toxins are unique because they contain a core chromophore of phenolic quinone that is able to absorb light energy (photosensitizers) and produce reactive oxygen species (ROS) such as the hydroxyl radical $\left(\mathrm{OH}^{*}\right)$, superoxide $\left(\mathrm{O}_{2}{ }^{-}\right)$, hydrogen peroxide $\left(\mathrm{H}_{2} \mathrm{O}_{2}\right)$, and singlet oxygen $\left({ }^{1} \mathrm{O}_{2}\right)$ (Daub and Ehrenshaft 2000; Daub et al. 2005). Although the biological functions of the light-activated perylenequinone toxins for the producing fungi remain largely unknown, their production by such a wide range of plant pathogens clearly suggests an important role for these toxins in fungal pathogenesis (Daub and Ehrenshaft 2000). Many perylenequinone toxins originally were investigated because of their possible pharmaceutical application (Hudson and Towers 1991) or because of their potential as food contaminants (Stack et al. 1986). In contrast, the role of these perylenequinone toxins relevant to the onset of plant diseases has been investigated very little compared with many other host-specific phytotoxins. Only cercosporin has been demonstrated genetically to play a crucial role in Cercospora diseases (Callahan et al. 1999; Choquer et al. 2005, 2007; Dekkers et al. 2007; Shim and Dunkle 2003; Upchurch et al. 1991).

Elsinochromes are red or orange pigments produced by a number of phytopathogenic Elsinö spp. Elsinochromes comprise at least four derivatives $(\mathrm{A}, \mathrm{B}, \mathrm{C}$, and $\mathrm{D})$ with a common perylenequinone backbone but differing in side groups (Weiss et al. 1987). The bright red pigments, elsinochromes A, B, and $\mathrm{C}$, originally were isolated from cultures of a pecan pathogen, Elsinoë randii (anamorph: Sphaceloma randii), and their chemical structures and physical properties have been well documented (Lousberg et al. 1969; Weiss et al. 1965). Elsinochromes $\mathrm{B}$ and $\mathrm{C}$ can be quickly oxidized to A by chromium trioxide (Lousberg et al. 1969). In contrast, elsinochrome D, likely derived from elsinochrome $\mathrm{C}$ by formation of a methylenedioxy ring, is an orange pigment produced by only some Elsinö spp. (Shirasugi and Misaki 1992).

E. fawcettii infects lemon, grapefruit, and some tangerine lines and their hybrids, producing exterior blemishes (citrus $\mathrm{scab}$ ) on the fruit, which is a serious problem for the fresh-fruit market worldwide. Isolates of E. fawcettii grow slowly in culture, producing a colony of $<10 \mathrm{~mm}$ in 30 days and never form fluffy mycelia. In previous studies, we extracted elsinochrome pigments from a field isolate of E. fawcettii and reported the production of ${ }^{1} \mathrm{O}_{2}$ and $\mathrm{O}_{2}{ }^{--}$by elsinochromes upon exposure to light (Liao and Chung 2008). We also showed that crude extracts containing a mixture of five elsinochrome derivatives 
from E. fawcettii cultures were highly toxic to suspension-cultured citrus and tobacco cells, and induced electrolyte leakage of host leaves after irradiation. The toxicity of elsinochromes was reduced considerably when ${ }^{1} \mathrm{O}_{2}$ quenchers such as bixin, ascorbate, and reduced glutathione were present. Furthermore, we demonstrated that elsinochromes alone induced necrotic lesions on rough lemon leaves following exposure to visible light, and the development of such lesions was impeded by coapplying ${ }^{1} \mathrm{O}_{2}$ quenchers (Liao and Chung 2008). Thus, we concluded that elsinochromes function as photosensitizing compounds and are toxic to plant cells by generating ${ }^{1} \mathrm{O}_{2}$ and $\mathrm{O}_{2}{ }^{--}$.

In this article, we report the cloning, coordinate expression, and functional characterization of the polyketide synthaseencoding gene, EfPKS1 that is required for the production of elsinochromes by creating and analyzing loss-of-function EfPKS1 mutants of E. fawcettii. The results indicate that elsinochromes are required for fungal pathogenesis.

\section{RESULTS}

\section{Cloning and characterization of the EfPKS1 gene.}

To conclusively determine the roles of elsinochromes in fungal colonization and lesion formation, we cloned and characterized a gene encoding fungal polyketide synthase (PKS) from E. fawcettii. A 0.7-kb DNA fragment was amplified from genomic DNA of $E$. fawcettii with degenerate primers designed to anneal to the conserved $\beta$-keto-synthase (KS) domain of many type-I fungal PKSs. Sequence analysis revealed that the amplified fragment has strong similarity to the KS domain of PKSs. The gene was named EfPKS1 (E. fawcettii PKS gene 1). Subsequently, the entire EfPKSI open reading frame (ORF) sequences as well as its $5^{\prime}$ and $3^{\prime}$ nontranslated regions were obtained by multiple rounds of polymerase chain reaction (PCR) from a chromosome walking library or with two inverse primers from restriction enzyme-digested and self-ligated DNA pools. As a result, over $8 \mathrm{~kb}$ of genomic sequences were sequenced, assembled, and deposited within EMBL/GenBank Data Libraries under the accession number EU086466.

Computer prediction and comparison between cDNA and genomic DNA sequences revealed that EfPKS1 contains two exons interrupted by a 52-bp intron near the 5' end of EfPKS1 (data not shown). The intron has characteristic splicing (5'-/gt--ag/-3') and internal lariat (cta/gat/c) consensus sequences often found in genes of filamentous fungi. Conceptual translation revealed that EfPKSI encodes a polypeptide containing 2,192 amino acids that displays considerable similarity and identity to numerous type-I PKSs of fungi, particularly those involved in pigment formation and biosynthesis of secondary metabolites (Fig. 1). Similar to many fungal type-I PKSs, the translated product of EfPKSI has a KS domain, an acyl transferase (AT) domain, two acyl carrier protein (ACP) domains, and a thioesterase/claisen cyclase (TE/CYC) domain (Fig. 1A). Phylogenetic relationships of EfPKS1 to other fungal PKSs, inferred from the conserved KS or AT domain, revealed that EfPKS1 is highly similar to the fungal nonreducing PKSs, including those involved in the biosynthesis of melanin, cercosporin, bikaverin, sirodesmin, aflatoxin, and other pigments (Fig. 1B and C).

\section{Promoter analysis of the EfPKS1 gene.}

To gain a better understanding of the regulation of EfPKS1 gene expression, we analyzed $1.1-\mathrm{kb}$ sequences upstream of the putative ATG translational start codon of EfPKS1 and identified several putative binding sites for diverse transcriptional regulators (Fig. 2). A TATA box-like sequence (TATATC) on the sense strand was identified 264 nucleotides upstream from the ATG codon. The promoter region of EfPKS1 has multiple
GATA consensus motifs, potential binding sites for the nitrogen-induced AreA (Marzluf 1997) and the light-regulated WC1/WC2 (Linden and Macino 1997) transcriptional activators. The EfPKS1 promoter contains four ambient $\mathrm{pH}$-regulated PacC-binding consensus motifs (GCCARG) (Espeso et al. 1997) and multiple cAMP-inducible C/EBP-binding motifs (CCAAT or CAAT) (Rangan et al. 1996). In addition, the EfPKS1 promoter contains three MRAGGGR and two CATTCY consensus motifs that have been shown to serve as binding sites for the conidial formation-related BrlA and AbaA transcriptional activators in Aspergillus nidulans (Adams et al. 1998). Analysis of the complementary strand of the EfPKSI promoter also identified multiple AreA, WC complex, PacC, $\mathrm{C} / \mathrm{EBP}$, and BrlA binding motifs (Fig. 2).

\section{Expression and regulation}

of the EfPKS1 gene and elsinochrome production.

To determine the factors affecting elsinochrome production and expression of the EfPKSl gene, fungal cultures were grown on media with different carbon and nitrogen sources or $\mathrm{pH}$ values, or incubated in the light or complete darkness. Elsinochromes were extracted and analyzed by spectrophotometry and total RNA was extracted and analyzed by Northern blot hybridization. A time-course analysis of EfPKS1 RNA levels and elsinochrome production revealed that the EfPKS1 gene transcript accumulated to a detectable level by day 3 and was drastically elevated by days 4 and 5 (Fig. 3A). Similarly, elsinochromes were detected at low concentrations at days 3 and 4 , yet accumulated rapidly to high levels at day 5. Accumulation of EfPKS1 transcript and elsinochromes was much higher when fungal cultures were incubated under continuous light compared with those grown in complete darkness (Fig. 3B). The EfPKS1 gene was preferentially expressed and elsinochromes accumulated to high levels when E. fawcettii was cultured in glucose-rich medium under illumination (Fig. 3C). By contrast, deprivation of ammonium nitrate stimulated the accumulation of both the EfPKS1 transcript and elsinochromes (Fig. 3D). Both the expression of EfPKSI and production of elsinochromes appeared to be favorable when the fungus was grown under alkaline conditions (Fig. 3E).

\section{EfPKS1 is required for elsinochrome production.}

The function of EfPKSI in relation to elsinochrome production was determined by targeted gene disruption in E. fawcettii. A disruption plasmid (pPKS0311) carrying the hygromycin phosphotransferase B gene $(H Y G)$ cassette flanked by truncated EfPKSI sequences on both sides was constructed. Two separate DNA fragments overlapping within the $H Y G$ gene (Fig. 4A) were amplified and directly transformed into wild-type $E$. fawcettii for targeted gene disruption. In total, 600 transformants were recovered from media containing hygromycin. Among them, approximately 100 transformants failed to accumulate red or orange pigments on potato dextrose agar (PDA) after 30 days of incubation under constant light and were considered putative EfPKS1 mutants. Southern blot analysis of genomic DNA isolated from 13 putative EfPKSI mutants revealed that all transformants tested were missing the expected $3.5-\mathrm{kb}$ hybridizing band of the wild type, when fungal DNA was cleaved with restriction endonuclease $\mathrm{Cla}$ I and hybridized to probe I that recognizes sequences in the $5^{\prime}$ end of EfPKS1 (Fig. 4B; data not shown). All 13 transformants displayed a 5.1-kb hybridizing band as a result of $H Y G$ insertion within EfPKS1. Four mutants had a single 5.1-kb hybridizing band (Fig. 4B), whereas the other nine mutants displayed additional hybridizing signals larger or smaller than $5.1 \mathrm{~kb}$ (data not shown), likely resulting from ectopic insertions. When fungal genomic DNA was cleaved with $X b a I$ and hybridized to probe II that recognizes the $3^{\prime}$ end 
sequences of EfPKS1, an expected 7.9-kb band was detected in the wild type (Fig. 4C). By contrast, all 13 transformants had a single 4.6-kb hybridizing band resulting from the $H Y G$ insertion at the EfPKS1 locus (Fig. 4C; data not shown). The hybridiza- tion profiles obtained from Southern blot analysis with two different probes clearly indicate that EfPKS1 of each transformant was replaced with the $H Y G$ gene cassette via homologous integration.

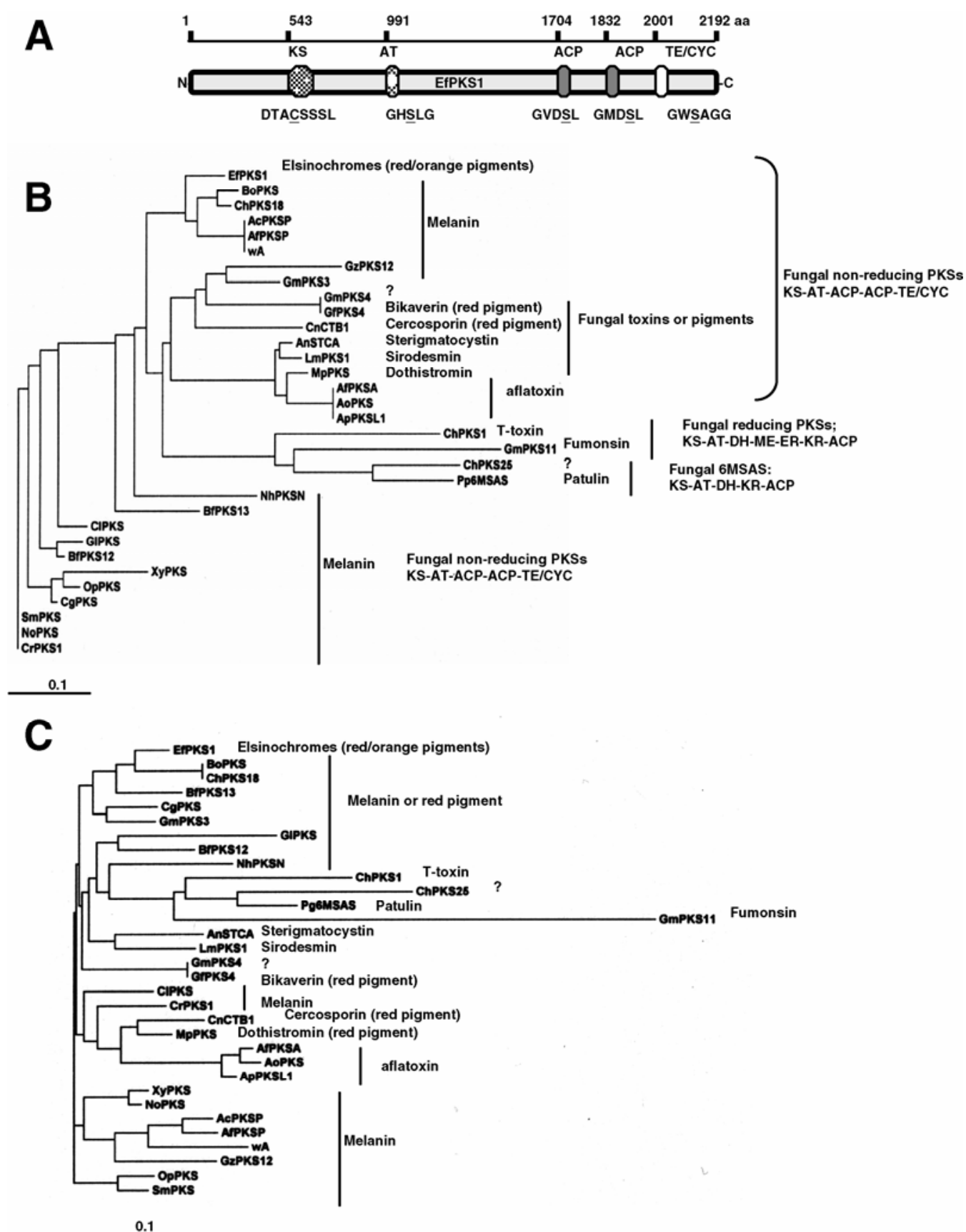

Fig. 1. A, Schematic illustration of the putative polyketide synthase, EfPKS1 containing 2,192 amino acids in Elsinoë fawcettii, showing a keto synthase (KS) domain with acyl-binding cysteine, an acyl transferase (AT) domain containing pantotheine-binding serine, a thioesterase/claisen cyclase motif (TE/CYC), and two acyl carrier protein (ACP) domains containing phosphopantotheine-binding serine. Conserved amino acids for each of the domains also are indicated under the map, and the active amino acids are underlined. EfPKS1 lacks dehydratase (DH), enoyl reductase (ER), $\beta$-ketoacyl reductase (KR), and methyltransferase (ME) domains. B and $\mathbf{C}$, Phylogenetic relationships of EfPKS1, based on the conserved amino acids in the B, KS or $\mathbf{C}$, AT domain, to other fungal polyketide synthases (PKSs) (accession number), including Bipolaris oryzae BoPKS (BAD22832); Cochliobolus heterostrophus ChPKS18 (AAR90272); Botryotinia fuckeliana BfPKS13 (AAR90249); Xylaria sp. XyPKS (AAM93545); Nodulisporium sp. NoPKS (AAD38786); Ophiostoma piceae OpPKS (ABD47522); Glarea lozoyensis GIPKS (AAN59953); Colletotrichum lagenarium ClPKS1 (BAA18956); Sordaria macrospore SmPKS (CAM35471); Aspergillus clavatus AcPKSP (XP_001276035); Ceratocystis resinifera CrPKS1 (AAO60166); B. fuckeliana BfPKS12 (AAR90248); A. fumigatus AfPKSP (AAC39471); Chaetomium globosum CgPKS (XP_001219763); Emericella nidulans wA (1905375A); Nectria haematococca NhPKSN (AAS48892); Gibberella zeae GzPKS12 (AAU10633); A. nidulans AnSTCA (XP_681094); C. heterostrophus ChPKS19 (AAR90273); Cercospora nicotianae CnCTB1 (AAT69682); G. moniliformis GmPKS3 (AAR92210); G. moniliformis GmPKS4 (AAR92211); G. fujikuroi GfPKS4 (CAB92399); Mycosphaerella pini MpPKS (AAZ95017); A. flavus AfPKSA (AAS89999); A. oryzae AoPKS (BAE71314); A. parasiticus ApPKSL1 (Q12053); Leptosphaeria maculans LmPKS1 (AAS92537); C. heterostrophus ChPKS1 (AAB08104); G. moniliformis GmPKS11 (AAR92218); C. heterostrophus ChPKS25 (AAR90279); and Penicillium patulum Pm6MSAS (P22367). The phylogram was created with the program PHYLP (Saitou and Nei 1987). 
Successful disruption of EfPKS1 was confirmed further by Northern blot analysis (Fig. 5A). The DNA probe (Fig. 4, no. 3) hybridized to total RNA of the wild type, displaying a 6.6$\mathrm{kb}$ hybridizing signal. However, the probe failed to detect the EfPKS1 transcript in three randomly selected mutants, indicting that they are EfPKS1-null mutants. Quantitative assays of elsinochrome production by the EfPKS1 null mutants after $\mathrm{KOH}$ extraction revealed that the null mutants did not accumulate any measurable elsinochromes compared to wild type (Fig. 5B). No elsinochromes were detected from the acetone extracts of four null mutants on thin-layer chromatography (TLC), indicating that disruption of EfPKS1 completely obliterated elsinochrome production (Fig. 5C).

Genetic complementation experiments revealed that the elsinochrome-deficient phenotype of a null mutant (D4) was restored by acquiring and expressing a functional EfPKSI gene with its endogenous promoter (Fig. 5C), further confirming the requirement for EfPKSI in elsinochrome production in E. fawcettii.
Disruption of EfPKS1 reduces conidiation.

The EfPKS1 null mutants displayed normal radial growth comparable with the wild type, yet produced far fewer conidia relative to the wild type (Table 1). Genetic complementation, by introducing a functional copy of the EfPKS1 gene into protoplasts of the D4 null mutant, resulted in two transformants with restored conidial production (Table 1), indicating a close link between EfPKS1 function and conidiation.

The EfPKS1 gene is required for full virulence.

Because all EfPKS1 null mutants were severely defective in conidial production, fungal pathogenicity first was evaluated on detached rough lemon leaves inoculated with agar plugs cut from fungal mycelium (without conidia). Inoculation of wildtype and two genetically reverted strains $(\mathrm{C} 1$ and $\mathrm{C} 2)$ resulted in pink to light-brown scab lesions with round pustules around the edges, whereas EfPKS1 null mutants did not incite any visible lesions (Fig. 6). Quantitative assays indicated that over $65 \%$ of spots inoculated with agar plugs cut from the cultures

\section{EfPKS1 promoter}

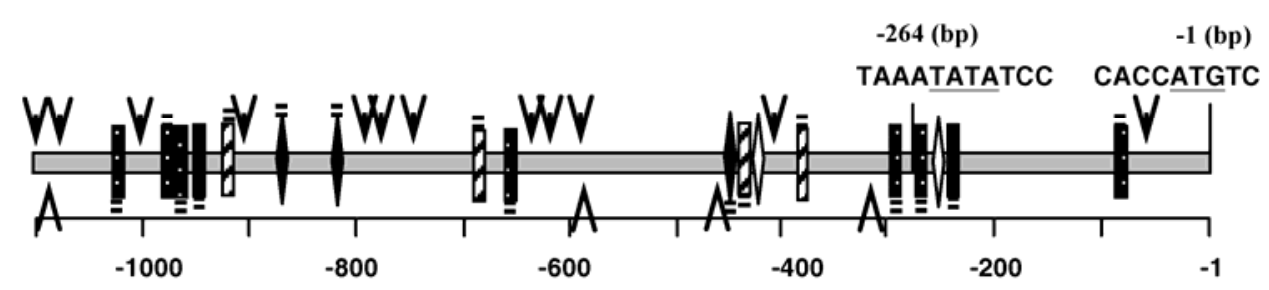

\begin{tabular}{|c|c|c|c|c|}
\hline Symbol & $\begin{array}{l}\text { Conserved } \\
\text { elements }\end{array}$ & Numbers (Sites) & $\begin{array}{l}\text { Transcriptional } \\
\text { factor }\end{array}$ & $\begin{array}{l}\text { Genes of } \\
\text { activation }\end{array}$ \\
\hline
\end{tabular}

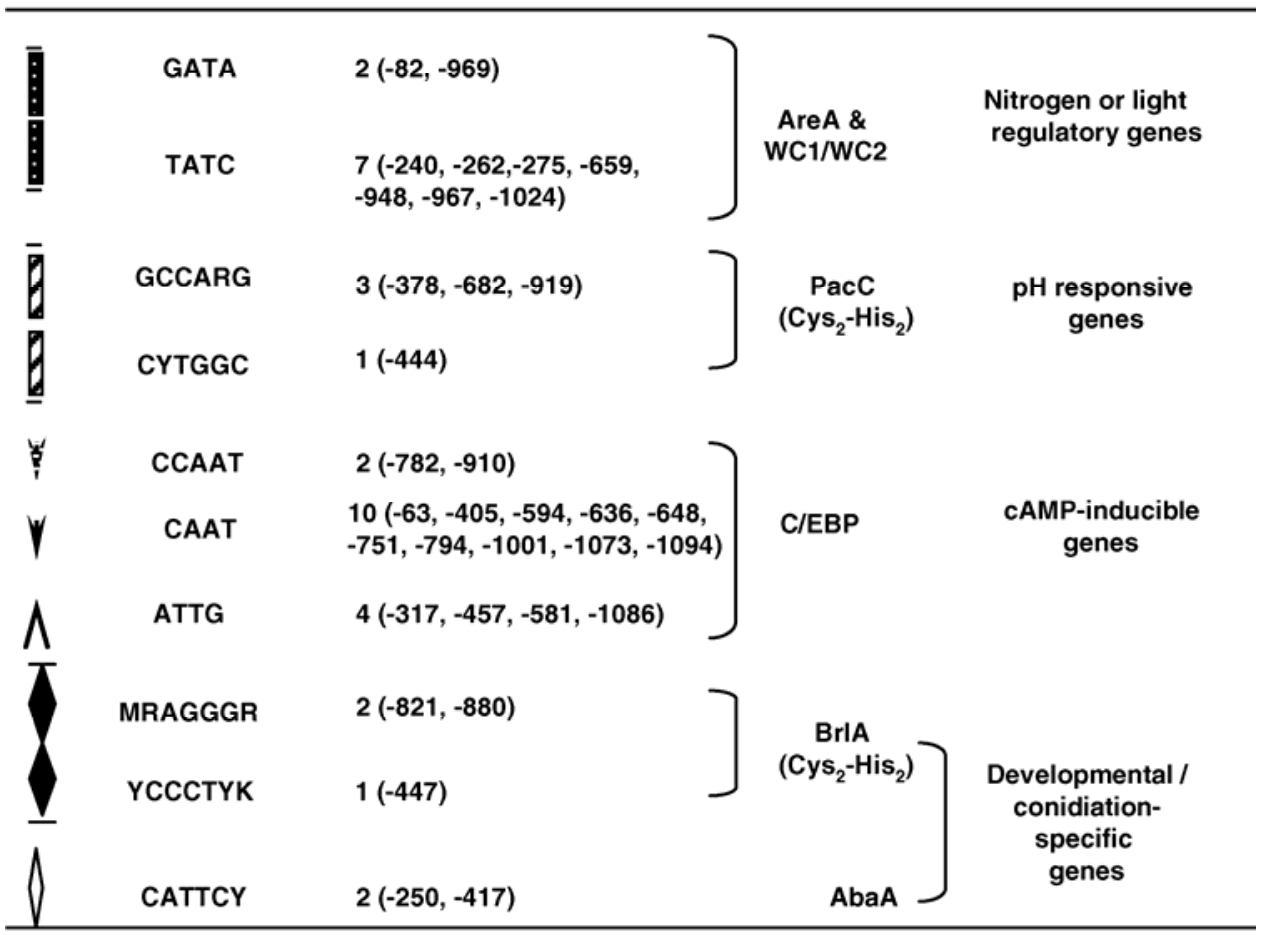

Fig. 2. Promoter analysis of 1.1-kb sequences upstream of the putative ATG translational start codon of EfPKS1 in both directions, identifying a number of putative binding sites for global transcriptional regulators such as AreA (nitrogen regulatory protein), the WC1/WC2 complexes (light regulatory proteins), PacC (ambient $\mathrm{pH}$ regulatory protein), and C/EBP (cAMP-activated protein). The EfPKS1 promoter also has conserved sequences for recognition and binding of the conidial formation-associated BrlA and AbaA transcriptional activators in Aspergillus nidulans. Definition of mixed bases: $\mathrm{R}=\mathrm{A}$ or $\mathrm{G} ; \mathrm{M}=\mathrm{A}$ or $\mathrm{C} ; \mathrm{Y}=\mathrm{C}$ or $\mathrm{T}$ 
of wild-type or complementation strains developed necrotic lesions (Table 1). By contrast, none of the leaf spots inoculated with EfPKS1 null mutants or agar plugs alone displayed visible necrosis.

Pathogenicity assays also were performed on detached leaves inoculated with conidial suspension. In this assay, only the D4 null mutant was evaluated for pathogenicity because the other null mutants produced very few conidia. When assayed on young leaves (approximately 3 days after emergence), the D4 mutant induced necrotic lesions at rates and magnitudes indistinguishable from those induced by the wild type, and the C2 strain genetically expressing a functional EfPKS1 (Fig. 7A). The wild type and the $\mathrm{C} 2$ strain produced characteristic scab lesions when inoculated onto older leaves (approximately 7 days after emergence), whereas the D4 null mutant with similar amounts of conidia $\left(1 \times 10^{5}\right.$ conidia/ml $)$ obviously incited fewer and smaller lesions due to lack of the production of elsinochromes (Fig. 7B). Nevertheless, disruption of EfPKS1 yielded mutants that were completely devoid of elsinochrome production and drastically defective in conidiation and scab lesion formation, indicating that production of elsinochromes is one of the fungal virulence determinants in E. fawcettii.

\section{DISCUSSION}

Elsinochromes, produced by many phytopathogenic fungi of the Elsinö̈ genus, consist of at least four derivatives differing mainly in their side groups. In the present study, we isolated the fungal EfPKS1 gene, demonstrated its requirement in elsinochrome biosynthesis, and conclusively showed that elsinochromes play a role in fungal virulence. The results also indicate that elsinochromes are synthesized via a fungal polyketide pathway.

As with many type-I fungal PKSs (Choquer et al. 2005; Keller et al. 2005; Kroken et al. 2003), the EfPKS1 product contains five functional domains, including a KS, an AT, a TE/CYC, and two ACP domains, which are involved in catalyzing iterative condensations of acetates and malonates, and chain elongation and cyclization of polyketomethylenes (Watanabe and Ebizuka 2004). EfPKS1 also has a conserved cysteine residue in the $\mathrm{KS}$ domain and conserved serine residues in the AT, ACP, and TE/CYC domains, similar to other fungal PKSs belonging to the nonreducing group (Kroken et al. 2003). Integration of a hygromycin-resistance gene cassette specifically at the EfPKSI locus resulted in fungal mutants that are completely devoid of elsinochrome production, severely defective in sporulation, and delayed in lesion development on older, rough lemon leaves. The mutant phenotypes were fully complemented in a strain that genetically acquired and functionally expressed a copy of EfPKS1, confirming that EfPKS1 is responsible for the observed deficiencies and that elsinochromes are important virulence factors. Pathogenicity assays on detached rough lemon leaves revealed that E. fawcettii incites more severe necrotic lesions when inoculated with conidial inoculation compared with mycelium cut from agar plugs. Although the EfPKS1 null mutants also were defective in conidial formation, reduction of fungal virulence was attributed mainly to the impairment of elsinochrome production rather than conidial formation and germination. When pathogenicity was evaluated with conidial suspension, the D4 null mutant induced scab lesions on young leaves (3 days after emergence), comparable with those induced by the wild type. Hence, the EfPKSInull mutant was apparently not deficient in conidial germination. However, the D4 null mutant induced fewer lesions on older leaves (7 days after emergence) strongly indicating that production of elsinochromes is essential for full virulence of $E$. fawcettii.

Expression of the EfPKS1 gene appears to be well correlated with accumulation of elsinochromes. The EfPKS1 transcript and elsinochromes accumulated to high levels when the fungus was grown in the light, in the presence of higher amounts of glucose, at alkaline $\mathrm{pH}$, or in the absence of a nitrogen source. Differential expression of EfPKS1 in response to various environmental conditions was supported further by analyzing the promoter region for putative DNA binding sites for global transcriptional activators. For example, two GATA consensus sites, presumably involved in the binding of the AreA/Nit2 nitrogen regulatory proteins (Marzluf 1997) or the WC1/WC2 light responsive transcriptional regulators (Linden and Macino 1997) were identified. The promoter region of EfPKS1 has

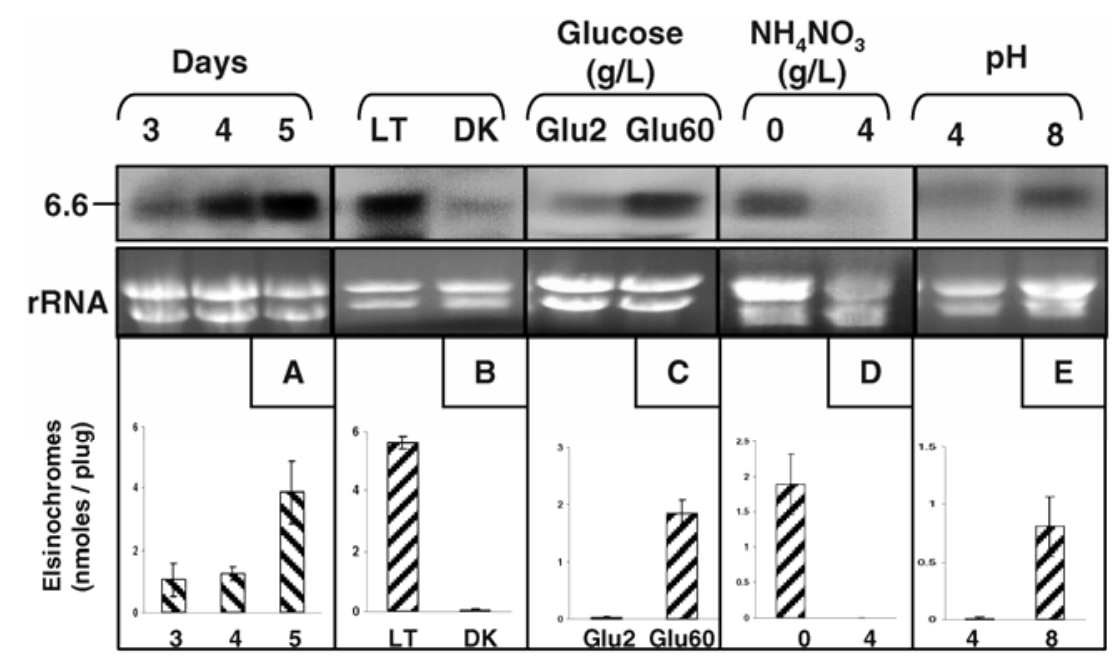

Fig. 3. Differential expression of the EfPKS1 gene encoding a fungal polyketide synthase and accumulation of elsinochrome phytotoxins in a wild-type isolate of Elsinö fawcettii. Fungal isolate was grown on $\mathbf{A}$ and $\mathbf{B}$, potato dextrose agar, $\mathbf{C}$, complete medium containing different amounts of glucose, or on minimal medium containing D, different concentrations of ammonium nitrate or $\mathbf{E}$, with different pH values under continuous light (LT) or darkness (DK). Unless indicated, fungal RNA was isolated from 7-day-old cultures, electrophoresed in an agarose gel containing formaldehyde, transferred onto a nylon membrane, and hybridized to an EfPKS1 gene-specific probe. Ribosomal RNA (rRNA) stained with ethidium bromide is shown for relative loading of the samples. Elsinochromes were extracted with $5 \mathrm{~N} \mathrm{KOH}$ and measured at an absorbance of 480 nm. The amounts of elsinochromes were determined by reference to a regression line that was established using ethyl acetate-purified cercosporin. Elsinochrome data represent the means and standard errors of two different experiments with four replicates of each treatment. 
three consensus GCCARG motifs that likely are involved in the binding of the $\mathrm{pH}$-responsive transcriptional regulator, PacC (Espeso et al. 1997). The EfPKS1 promoter also has multiple CCAAT or CAAT consensus motifs involved in binding cAMP-activated proteins such as CCAAT/enhancer-binding protein (C/EBP) (Ramji and Foka 2002).

In addition to complete abrogation of elsinochrome production, EfPKS1 null mutants also were severely defective in conidial production. The elsinochrome-producing phenotype and conidiation were fully restored by expressing a dominantactivated allele of an E. fawcettii EfPKS1 protein in a null mutant. These findings indicate a tight connection between elsinochrome biosynthesis and conidiation. It has long been known that production of natural compounds by microorganisms often is linked with cell development or differentiation (Adams and Yu 1998; Brodhagen and Keller 2006; Calvo et al. 2002; Yu and Keller 2005). It appears that both conidiation and production of secondary metabolites in fungi respond to common environmental cues, subsequently trigger signaling transduction pathways, and regulate gene expression inside the cells. It is well known that environmental factors such as light, the types of carbon and nitrogen sources, and ambient $\mathrm{pH}$ via a
PacC-mediated pathway regulate both developmental differentiation and biosynthesis of secondary metabolites in various fungi (Calvo et al. 2002). The genetic mechanisms linking both processes are multifaceted and beginning to be unveiled through molecular studies in several fungal species. The involvement of a G-protein/cAMP/protein kinase A-mediated pathway in both asexual sporulation and mycotoxin production in $\mathrm{A}$. nidulans has provided significant insight into the close regulatory interactions between these two phenotypes in other fungi. In addition, the mitogen-activated protein (MAP) kinase and cyclin-dependent kinase pathways also have been shown to regulate both conidiation and production of cercosporin in Cercospora zeae-maydis (Shim and Dunkle 2003) and fumonisins in Fusarium verticillioides (Shim and Woloshuk 2001), respectively. Other cellular regulators such as oxylipins and other lipid derivatives, polyamines, the CCAAT-binding protein complex, and the proteins containing Trp-Asp (WD) repeats also have been shown to coordinate regulation of both secondary metabolite production and sporulation in Aspergillus spp. (Calvo et al. 2002; Tsitsigiannis and Keller 2006).

Coordinate regulation for conidiation and production of elsinochromes by E. fawcettii may mediate similar regulatory path-

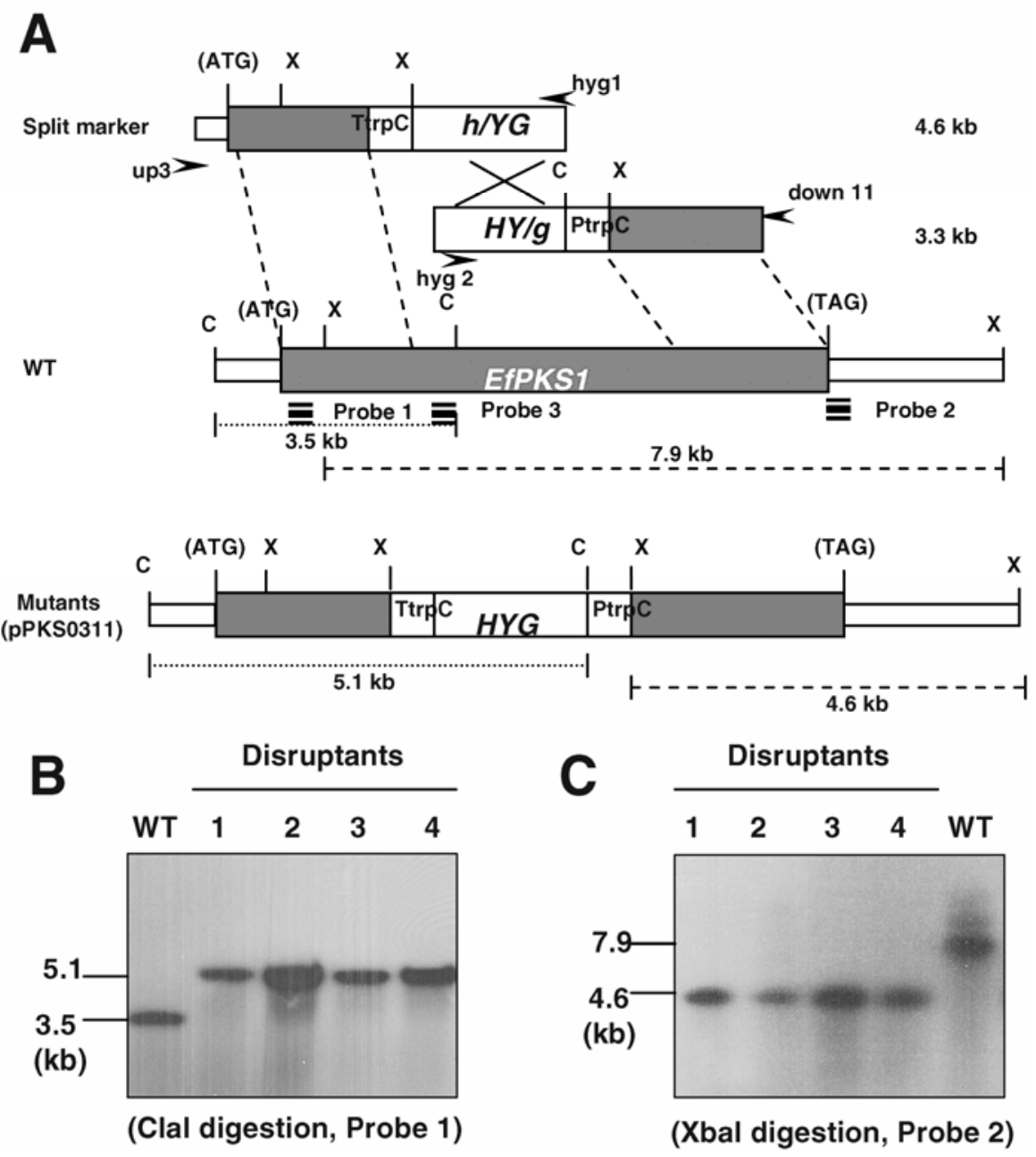

Fig. 4. A, Schematic depicting a split-marker strategy for EfPKS1 (indicated by shaded columns) targeted disruption in Elsinoë fawcettii. A 4.6-kb DNA fragment containing the 5' end of EfPKSI fused with the TrpC terminator of Aspergillus nidulans and truncated hygromycin phosphotransferase B gene $(h / Y G)$ and a 3.3$\mathrm{kb}$ fragment containing the $3^{\prime}$ end of EfPKS1 joined with the $\operatorname{Trp} C$ promoter and truncated $H Y / g$ were amplified from the disruption construct pPKS0311 with the primers as indicated. The $h / Y G$ and $H Y / g$ fragment share $400 \mathrm{bp}$ of overlapping sequence. The split-marker fragments were transformed directly into protoplasts of the E. fawcettii wild-type strain for targeted gene disruption via double crossing-over recombination. The relative locations of DNA probes used for Southern and Northern blot analyses also are indicated. Abbreviations for restriction endonuclease sites: C, ClaI; X, XbaI. B, Southern blot analysis of genomic DNA from the wild type (WT) and four putative EfPKS1 disruptants (D1, D2, D3, and D4). Fungal DNA was cleaved with endonuclease ClaI, electrophoresed, blotted to a nylon membrane, and hybridized with the probe 1 . C, Southern blot analysis of genomic DNA digested with XbaI and hybridized with the probe 2. Sizes of hybridization bands are indicated in kilobase pairs $(\mathrm{kb})$. Banding patterns confirm disruption of the EfPKSI gene. 
ways, as described in Aspergillus spp. Such speculation is supported by analysis of the EfPKS1 promoter region, which identified multiple binding sequences for transcriptional activators, including GATA factors of nitrogen and light regulation, PacC of $\mathrm{pH}$ regulation, and the C/EBP-binding protein induced by cAMP. Furthermore, our results also revealed that production of elsinochromes via a defined polyketide pathway is highly affected at the transcriptional level by light, the levels of glucose and nitrogen sources, and $\mathrm{pH}$ values. In addition to the binding motifs for global regulatory proteins, the EfPKS1 promoter contains two distinct MRAGGGR motifs found in the promoter region of the gene encoding a conidiation-specific Bristle (BrlA) transcriptional activator of A. nidulans (Adams et al. 1998). Furthermore, the EfPKS1 promoter has two CATTCY motifs (Y is a pyrimidine) that serve as the binding sites for the AbaA transcriptional activator (Andrianopoulos and Timberlake 1994).

A

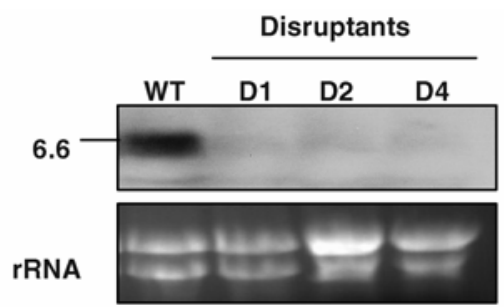

B
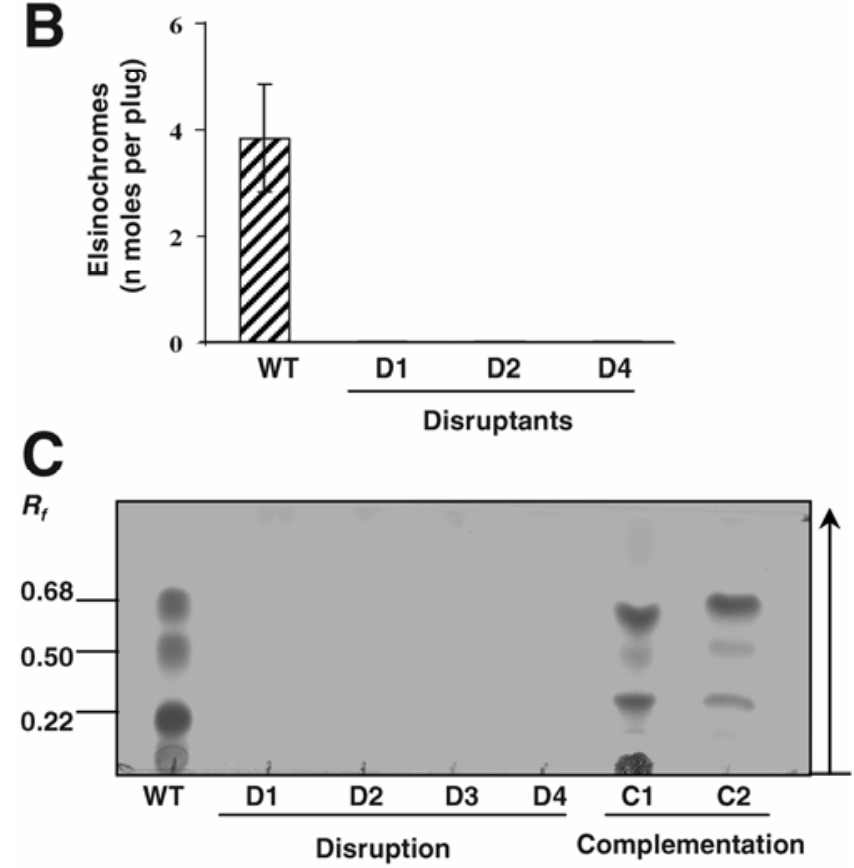

Fig. 5. A, Northern blot analysis of fungal RNA purified from the wild type (WT) and three putative EfPKS1 disruptants (D1, D2, and D4) of Elsinö̈ fawcettii. RNA was denatured in a formaldehyde-containing gel, blotted to a nylon membrane, and hybridized to a DNA probe (probe 3). Gel stained with ethidium bromide indicates relative loading of the RNA samples. Sizes of hybridization bands are indicated in kilobase pairs. B, Quantitative analysis of elsinochromes produced by the wild type and EfPKS1 disruptants. Fungal isolates were grown on potato dextrose agar under continuous light for 5 days. Elsinochrome pigments were extracted with $5 \mathrm{~N} \mathrm{KOH}$ from agar plugs covered with fungal hyphae and measured at an absorbance of $480 \mathrm{~nm}$. The concentrations of elsinochromes were calculated by referring to a regression line. Data represent the means and standard errors of two different experiments with four replicates of each treatment. $\mathbf{C}$, Thin-layer chromatography (TLC) analysis of elsinochromes extracted with acetone from the cultures of the wild type, four EfPKS1 disruptants, and two strains (C1 and C2) expressing a functional EfPKS1 gene. Elsinochromes were separated on a TLC plate coated with a 60 F254 fluorescent silica gel and developed with chloroform and ethyl acetate (1:1 by volume).
AbaA, regulated under BrlA, has been shown to be required for the final stages of conidiophore development in A. nidulans (Andrianopoulos and Timberlake 1994). The presence of conserved BrlA and AbaA binding elements in the promoter of EfPKS1 strongly suggests that the EfPKS1 product might be directly involved in conidial formation. Whether or not conidiation of E. fawcettii is regulated by light, $\mathrm{pH}$, carbon or nitrogen sources, or cAMP remains to be determined.

\section{MATERIALS AND METHODS}

\section{Fungal isolates and growth conditions.}

All fungal strains of Elsinoë fawcettii Bitanc. \& Jenkins (anamorph: Sphaceloma fawcettii Jenkins) were collected from citrus-growing areas in Florida and kindly provided by L. W. Timmer (University of Florida). A wild-type CAL WH-1 isolate, producing a large quantity of elsinochromes in cultures, was single-spore isolated from scab-affected calamondin (Citrus madurensis Lour) fruit and has been characterized previously (Liao and Chung 2008). Fungal isolates were maintained on PDA (Difco, Sparks, MD, U.S.A.). For toxin production, fungal mycelia were spread on PDA after grinding with a sterile blender and incubated under continuous fluorescent light for 5 days at room temperature (approximately $25^{\circ} \mathrm{C}$ ). For generation of protoplasts, fungal isolates were grown in $50 \mathrm{ml}$ of potato dextrose broth (PDB; Difco) for 7 days, ground, mixed with fresh PDB (200 ml), and incubated for an additional $15 \mathrm{~h}$. Fungal cultures used for DNA or RNA isolation were grown on media with a layer of sterile cellophane as previously described (Choquer et al. 2005). Complete medium (CM), minimal medium (MM), and protoplast regeneration medium (RMM) used in this study have been described elsewhere (Chung et al. 2002; Jenns et al. 1989). The $\mathrm{pH}$ of media was adjusted by $0.1 \mathrm{M}$ phosphate buffer as described (You et al. 2007).

\section{Extraction and analysis of elsinochrome toxin.}

Elsinochrome toxins were extracted twice from dried agar medium bearing fungal mycelia with acetone for $16 \mathrm{~h}$ and analyzed by spectrophotometry and TLC on a plate coated with 60 F254 fluorescent silica gel ( 5 by $20 \mathrm{~cm}$; Selecto Scientific Inc., Suwanee, GA, U.S.A.) as previously described (Liao and Chung

Table 1. Conidial production and lesion development ${ }^{\mathrm{a}}$

\begin{tabular}{lcc}
\hline $\begin{array}{l}\text { Fungal strains } \\
\text { or treatment }\end{array}$ & $\begin{array}{c}\text { Conidial formation } \\
(\text { conidia/ml) }\end{array}$ & $\begin{array}{c}\text { Spots with lesions/ } \\
\text { total spots }(\boldsymbol{\%})^{\mathbf{c}}\end{array}$ \\
\hline Wild type & $3.4 \pm 1.7 \times 10^{6}$ & $21 / 29(72)$ \\
D1 & $5.0 \pm 7.0 \times 10^{2}$ & $0 / 21(0)$ \\
D2 & $4.1 \pm 4.1 \times 10^{3}$ & $0 / 21(0)$ \\
D3 & $1.1 \pm 0.6 \times 10^{3}$ & $0 / 21(0)$ \\
D4 & $6.2 \pm 7.0 \times 10^{4}$ & $0 / 28(0)$ \\
C1 & $3.9 \pm 1.9 \times 10^{6}$ & $11 / 17(65)$ \\
C2 & $2.4 \pm 1.4 \times 10^{6}$ & $14 / 14(100)$ \\
Agar plugs & $\ldots$ & $0 / 50(0)$ \\
\hline
\end{tabular}

${ }^{a}$ Conidial production in axenic cultures and pathogenicity assays on detached rough lemon leaves by inoculating with agar plugs cut from cultures of Elsinoë fawcettii wild type; the EfPKS1 null mutants D1, D2, D3, and D4; and the strains C1 and C2 expressing a functional copy of EfPKS1.

${ }^{\mathrm{b}}$ Conidia were produced in Fries medium in the dark and were determined with the aids of a hemacytometer by microscopy. Data are means and standard errors of 10 different experiments with four replicates of each isolate.

${ }^{\mathrm{c}}$ Lesion development: leaf spots showing lesions/total spots inoculated (\%) A 4-mm agar plug cut from mycelial mats was placed onto detached rough lemon leaves. Inoculated leaves were incubated in a moist chamber under florescent light for 25 days. Lesion formation is indicated as the number of inoculated leaf spots developing scab lesions relative to the total number of spots inoculated. 
2008). There are no pure elsinochromes commercially available for purchase. In addition, cercosporin and elsinochromes, both containing phenolic quinones, have similar structures, molecular weight, and absorbance spectrum (Weiss et al. 1987). Hence, the concentration of elsinochromes was determined by reference to a regression line that was established using pure cercosporin (Sigma, St. Louis) as a standard. Quantitative analysis of the elsinochromes was performed by extracting agar plugs with fungal hyphae with $5 \mathrm{~N} \mathrm{KOH}$ and by measuring absorbance at 480 $\mathrm{nm}$. Screening of elsinochrome-deficient mutants was conducted on thin PDA as described (Chen et al. 2007; Choquer et al. 2005). Organic solvent was collected, air dried at room temperature, suspended in small volumes of acetone, and analyzed by spectrophotometry at an absorbance at $480 \mathrm{~nm}$ and TLC as previously described (Liao and Chung 2008).
Molecular cloning and analysis of the EfPKS1 gene.

Two degenerate oligonucleotides LCKS1 (5'-GTNCCNGTN CCRTGCATYTC-3') and LCKS2 (5'-GAYCCNMGNTTYTT YAAYATG-3') that are complementary to the conserved KS domain of fungal type-I PKS genes (Bingle et al. 1999) were synthesized and used for amplification from E. fawcettii genomic DNA using Taq DNA polymerase (GenScript, Piscataway, NJ, U.S.A.). The amplified DNA fragment (approximately $700 \mathrm{bp}$ ) was cloned into pGEM-T easy vector (Promega Corp., Madison, WI, U.S.A.) for sequencing from both directions at Eton Bioscience (San Diego, CA, U.S.A.). Sequences were blasted against the databases at the National Center for Biotechnology Information (NCBI) using the BLAST network service (Altschul et al. 1997) to determine the similarity of the amplified fragment. The full-length EfPKS1 gene was obtained by PCR using a chromo-
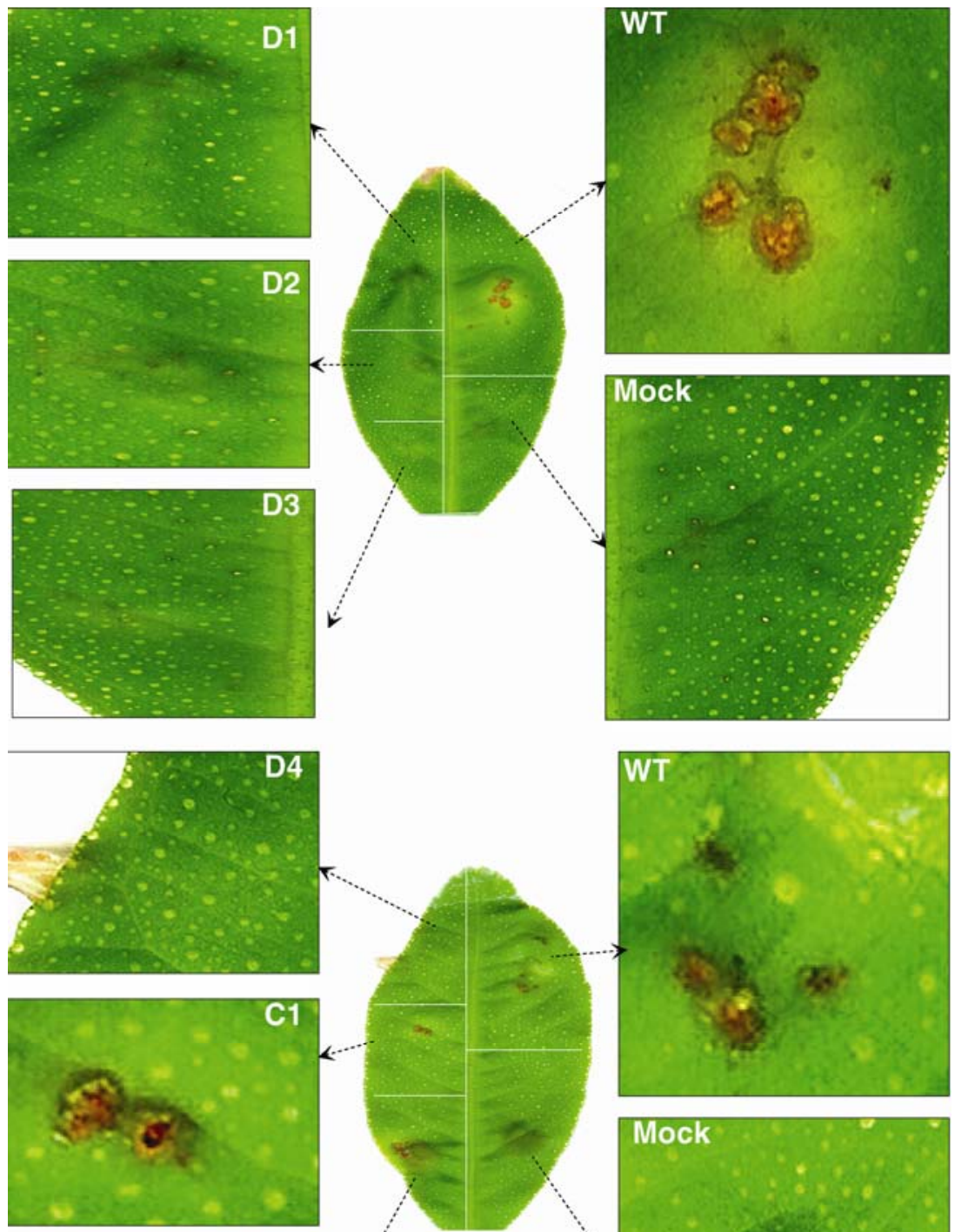

C1
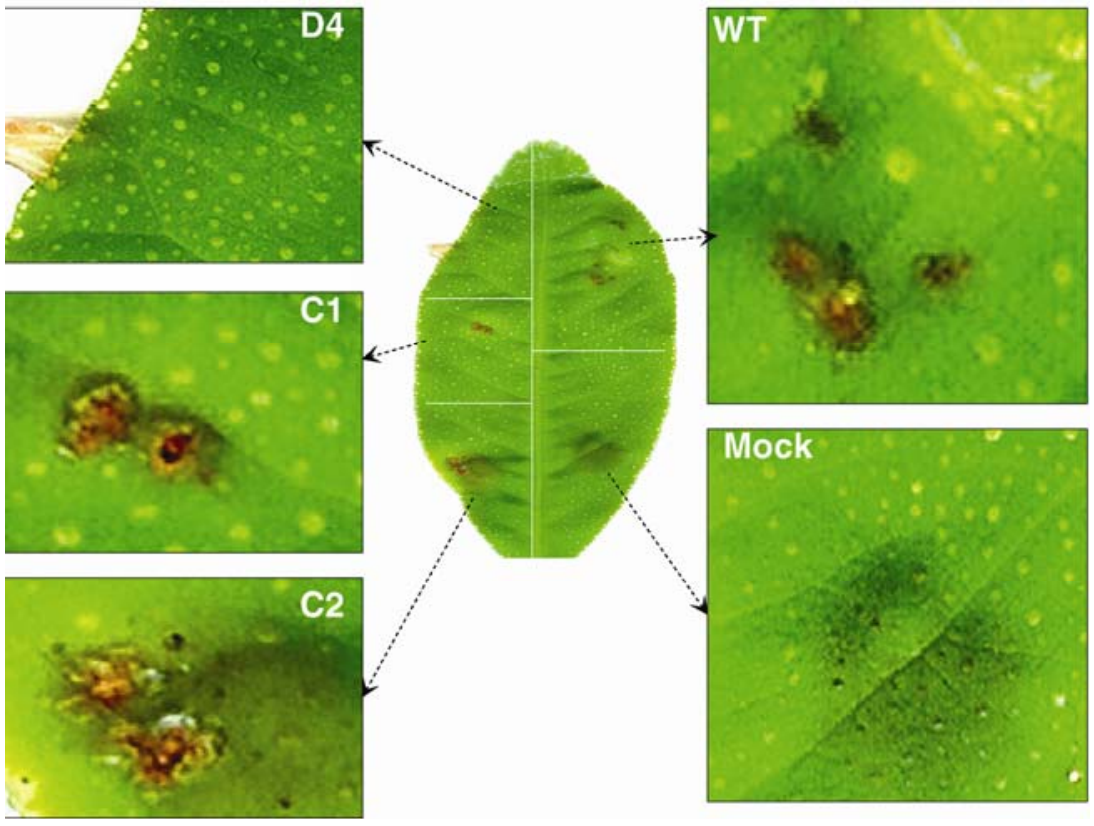

Fig. 6. Pathogenicity assays on detached rough lemon leaves inoculated with agar plugs (4 mm in diameter) of the wild type (WT), four EfPKS1 disruptants, and two strains (C1 and C2) expressing a functional EfPKS1 gene of Elsinoë fawcettii. Fungal isolates were grown on potato dextrose agar for 7 days and agar plugs covered with mycelial mats were cut and placed onto detached rough lemon leaves in which fungal mycelium directly contacts the leaf surface. Inoculated leaves (>20 leaves) were incubated for lesion development in a moist chamber under constant fluorescent light. Photos were taken 25 days postinoculation. The inoculated areas were cropped and enlarged for better illustration of necrotic lesions. The mocks were treated with agar plugs without fungal mycelium. 
some walking strategy as described previously (Chen et al. 2005; You et al. 2007) and by PCR with two inverse primers (Choquer et al. 2005). A chromosome library of E. fawcettii was prepared from genomic DNA cleaved with four different restriction enzymes, and ligated to the adaptors from the Universal GenomeWalker kit following the manufacturer's instructions (BD Biosciences, San Jose, CA, U.S.A.). To walk upstream and downstream into unknown genomic regions, primers were synthesized to complement the known regions and used for multiple rounds of PCR amplification with adaptor primers supplied with the kit. For PCR with inverse primers, fungal DNA was digested with restriction endonucleases, self-ligated, and used as a template for amplification. Oligonucleotide primers used for PCR amplification and sequence analysis were synthesized by Integrated DNA Technologies (Coralville, IA, U.S.A.) and Allele Biotechnology and Pharmaceuticals (San Diego, CA, U.S.A.), respectively. ORF and exon/intron positions were predicted using the Softberry gene-finding software and confirmed by comparisons of genomic and cDNA sequences. Function domains were predicted according to the PROSITE database using ExPASy (Gasteiger et al. 2003) or Motif/ProDom and Block programs (Henikoff et al. 2000). Analysis of the promoter region was conducted using regulatory sequence analysis tools (van Helden 2003).

\section{Targeted gene disruption.}

To disrupt the EfPKSI gene in E. fawcettii, a 5.8-kb DNA fragment encompassing the EfPKS1 ORF was obtained by PCR with primers efup3 (5'-caattacgcgaatgggtcacagagc- $\left.3^{\prime}\right)$ and efdown11 (5'-cgtcaaggacatcagcgagtc- $\left.3^{\prime}\right)$. The amplified DNA fragment was purified with a DNA purification kit (Mo Bio Laboratories, Carlsbad, CA, U.S.A.), and cloned into pGEM-T easy vector to create pSPKS0311. A 1.3-kb EcoRV$K p n I$ DNA fragment, corresponding to the conserved AT domain of EfPKS1, was removed and replaced with an end-filled 2.1-kb fragment harboring the $H Y G$ cassette under the control of the A. nidulans trpC gene promoter from pUCATPH (Lu et al. 1994) to yield the disruption construct, pPKS0311 (Fig. 4A). A split marker strategy was used to enhance the efficiency of double crossing-over recombination as previously described (Choquer et al. 2005). A 4.6-kb DNA fragment containing truncated 5' EfPKSI fused with 3' $H Y G$ and a 3.3-kb fragment encompassing 3' EfPKS1 joined with 5' $H Y G$ were amplified, respectively, with primers efup3/hyg1 (5'-aggagggcgtggatatgtc ctgcggg- $\left.3^{\prime}\right)$ and efdown11/hyg2 (5'-ccgacagtcccggctccggatc gg-3') from pPKS0311 using the Takara Ex Taq PCR system (Takara Bio USA, Madison, WI, U.S.A.). Fungal protoplasts were prepared by the method of Chung and colleagues (2002) except that hyphae were incubated with cell-wall-degrading enzyme cocktails for $6 \mathrm{~h}$. The resulting DNA fragments were mixed and transformed into protoplasts $\left(1 \times 10^{5}\right)$ of the wild type using $\mathrm{CaCl}_{2}$ and polyethylene glycol as previously described (Chung et al. 2002). The two hybrid fragments share $400 \mathrm{bp}$ of overlapping sequence within the $H Y G$ gene. The $H Y G$ gene is not functional unless recombination occurs between the two truncated $H Y G$ DNA fragments. Fungal transformants appearing on RMM medium supplemented with hygromycin at $200 \mu \mathrm{g} / \mathrm{ml}$ (Roche Applied Science, Indianapolis, IN, U.S.A.) after 2 to 3 weeks were selected and tested for lack of elsinochrome production (red or orange pigments) on thin PDA.

\section{Genetic complementation.}

For genetic complementation, a DNA fragment $(8.4 \mathrm{~kb})$, including the entire EfPKS1 ORF and its endogenous promoter, was amplified from genomic DNA with primers efup3 and efdown18 (5'-ctttcgtcgtcggcaccaac- $\left.3^{\prime}\right)$ by an Expand High Fi-

delity PCR system (Roche Applied Science) and co-transformed with plasmid pBarKS1 carrying a phosphinothrin acetyl transferase gene responsible for bialaphos resistance under control of the A. nidulans trpC promoter (Pall and Brunelli 1993) into an EfPKS1 disruptant (D4). Transformants were selected against DL-phosphinothricin at $100 \mu \mathrm{g} / \mathrm{ml}$ (chlorimuron ethyl; Chem Service, West Chester, PA, U.S.A.) and tested for restoration of elsinochrome production.

\section{Miscellaneous methods of processing nucleic acids.}

Fungal DNA was isolated with a DNeasy Plant kit (Qiagen, Valencia, CA, U.S.A.). Standard procedures were used for endonuclease digestion of DNA, electrophoresis, and Southern and Northern blot hybridizations. Plasmid DNA was purified using a Wizard DNA purification kit (Promega Corp.) from transformed Escherichia coli DH5 $\alpha$ bacterial cells. Fungal RNA was extracted with Trizol reagent (Invitrogen, Carlsbad, CA, U.S.A.). Double-strand cDNA of EfPKS1 was synthesized with a cDNA synthesis kit (BD Biosciences) following the manufacturer's instructions and amplified with gene-specific primers. The amplified fragments were purified and directly subjected to sequence analysis. DNA probes used for hybridization were labeled with digoxigenin (DIG)-11-dUTP (Roche Applied Science) by PCR with gene-specific primers. The manufacturer's
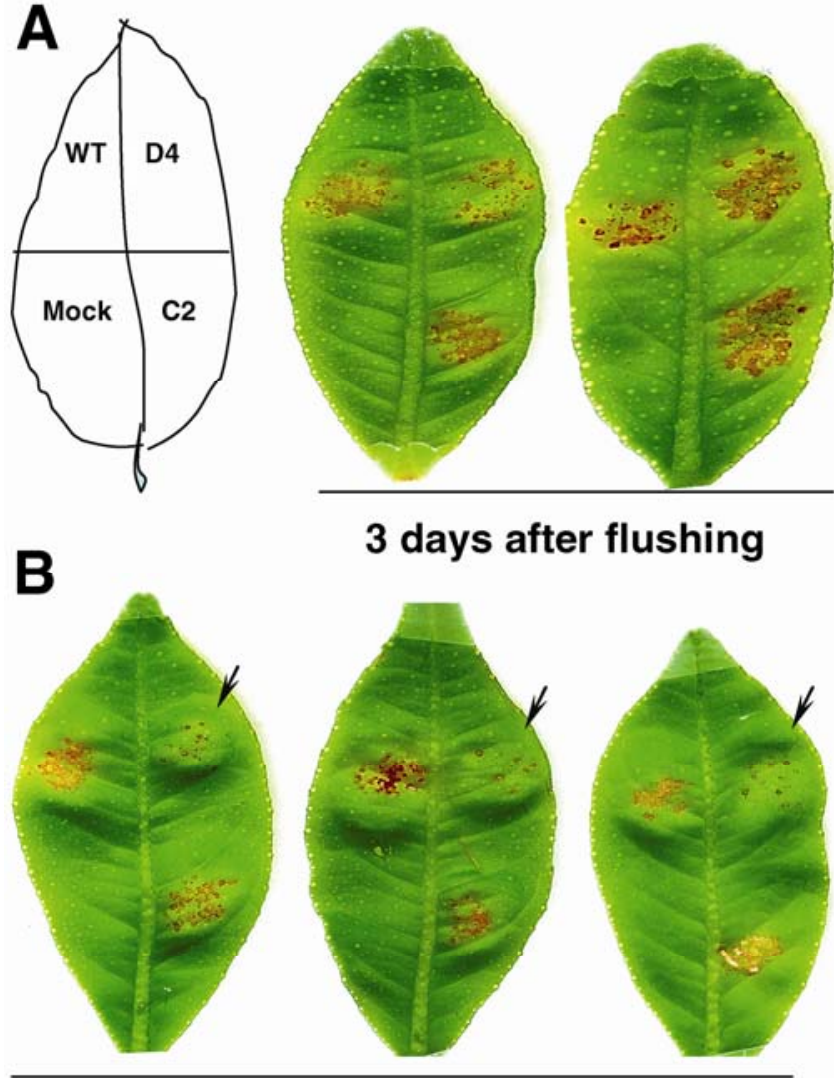

\section{7 days after flushing}

Fig. 7. Pathogenicity assays using conidial suspensions of the wild type (WT), the EfPKS1 disruptant (D4), and the complementation strain (C2) of Elsinö̈ fawcettii on detached rough lemon leaves $\mathbf{A}, 3$ or $\mathbf{B}, 7$ days after emergence. Fungal conidia $\left(1 \times 10^{5}\right.$ conidia/ml $)$ were harvested and applied by applying $2 \mu \mathrm{l}$ of suspension onto rough lemon leaves. Inoculated leaves (>20 leaves) were incubated in a moist chamber. Formation of lesions was recorded 14 days postinoculation. The mocks were inoculated with water only. Reduction in lesion numbers and sizes by inoculation of EfPKS1 disruptant (D4) are indicated by arrows. Only some of the representative replicates of the inoculated leaves are shown. 
recommendations were followed for probe labeling, hybridization, post-hybridization washing, and immunological detection of the probe using a CSPD chemofluorescent substrate for alkaline phosphatase (Roche Applied Science).

\section{Preparation of fungal inoculum and pathogenicity assays.}

Assays for fungal pathogenicity were conducted on detached rough lemon ( $C$. jambhiri Lush) leaves inoculated with conidial suspension or agar plugs covered with fungal hyphae. Rough lemon is susceptible to all Elsinoë pathotypes of citrus (Timmer et al. 1996). Conidia were prepared as described by Timmer and colleagues (1996) with modifications. Briefly, fungal hyphae were ground in Fries medium (Fries 1978), were placed on a petri dish ( 15 by $90 \mathrm{~mm})$, and were incubated for 2 to 3 days in the dark to trigger conidial formation. Rough lemon trees were maintained in a greenhouse and leaves of approximately 13 to $20 \mathrm{~mm}$ in length and 4 to $7 \mathrm{~mm}$ in width 4 to 7 days after flushing were collected for pathogenicity assays. Conidial suspension $\left(2 \mu \mathrm{l}, 1 \times 10^{5}\right.$ per milliliter) was carefully placed on the leaves and the inoculated leaves were incubated in a mist chamber under constant fluorescence light for lesion formation. Pathogenicity also was evaluated using agar plugs. Briefly, PDA agar plugs (4 $\mathrm{mm}$ in diameter) were cut from mycelial mats cultured on PDA for 7 days and placed on the underside of rough lemon leaves (approximately 12 days after emergence). The inoculated leaves were incubated in a mist chamber and examined for lesion formation daily.

\section{ACKNOWLEDGMENTS}

This research was supported by the Florida Agricultural Experiment Station and grants from the Florida Citrus Production Research Advisory Council (FCPRAC) no. 012-04P and no. 033-03P. We thank D. Henderson for editing and two anonymous reviewers for their helpful comments.

\section{LIERATURE CITED}

Adams, T. H., and Yu, J. H. 1998. Coordinate control of secondary metabolite production and asexual sporulation in Aspergillus nidulans. Curr. Opin. Microbiol. 1: 674-677.

Adams, T. H., Wieser, J. K., and Yu, J.-K. 1998. Asexual sporulation in Aspergillus nidulans. Microbiol. Mol. Biol. Rev. 62:35-54.

Ahonsi, M. O., Maurhofer, M., Boss, D., and Defago, G. 2005. Relationship between aggressiveness of Stagonospora sp. isolates on field and hedge bindweeds, and in vitro production of fungal metabolites cercosporin, elsinochrome A and leptosphaerodione. Eur. J. Plant Pathol. 111:203-215.

Altschul, S. F., Madden, T. L., Schaffer, A. A., Zhang, J., Zhang, Z., Miller, W., and Lipman, D. J. 1997. Gapped BLAST and PSI-BLAST: A new generation of protein database search programs. Nucleic Acids Res. 25:3389-3402.

Andrianopoulos, A., and Timberlake, W. E. 1994. The Aspergillus nidulans abaA gene encodes a transcriptional activator that acts as a genetic switch to control development. Mol. Cell. Biol. 14:2503-2515.

Arnone, A., Assante, G., Di Modugno, V., Merlini, L., and Nasini, G. 1988. Perylenequinones from cucumber seedlings infected with Cladosporium cucumerinum. Phytochemistry 6:1675-1678.

Bingle, L. E. H., Simpson, T. J., and Lazarus, C. M. 1999. Ketosynthase domain probes identify two subclasses of fungal polyketide synthase genes. Fungal Genet. Biol. 26:209-223.

Brodhagen, M., and Keller, N. P. 2006. Signalling pathways connecting mycotoxin production and sporulation. Mol. Plant Pathol. 7:285-301.

Callahan, T. M., Rose, M. S., Meade, M. J., Ehrenshaft, M., and Upchurch, R. G. 1999. CFP, the putative cercosporin transporter of Cercospora kikuchii, is required for wild type cercosporin production, resistance, and virulence on soybean. Mol. Plant-Microbe Interact. 12:901-910.

Calvo, A. M., Wilson, R. A., Bok, J. W., and Keller, N. P. 2002. Relationship between secondary metabolism and fungal development. Microbiol. Mol. Biol. Rev. 66:447-459.

Chen, H.-Q., Dekkers, K. L., Rollins, J. A., Ko, N. J., Timmer, L. W., and Chung, K.-R. 2005. A gene with domains related to transcription regulation is required for pathogenicity in Colletotrichum acutatum causing Key lime anthracnose. Mol. Plant Pathol. 6:513-525.
Chen, H. Q., Lee, M. H., Daub, M. E., and Chung, K.-R. 2007. Molecular analysis of the cercosporin biosynthetic gene cluster in Cercospora nicotianae. Mol. Microbiol. 64:755-770.

Choquer, M., Dekkers, K. A., Chen, H.-Q., Cao, L., Ueng, P. P., Daub, M. E., and Chung, K.-R. 2005. The CTB1 gene encoding a fungal polyketide synthase is required for cercosporin biosynthesis and fungal virulence of Cercospora nicotianae. Mol. Plant-Microbe Interact. 18:468-476.

Choquer, M., Lee, M. H., Bau, H. J., and Chung, K.-R. 2007. Deletion of a MFS transporter-like gene in Cercospora nicotianae reduces cercosporin toxin accumulation and fungal virulence. FEBS (Fed. Eur. Biochem. Soc.) Lett. 581:489-494.

Chung, K.-R., Shilts, T., Li, W., and Timmer, L. W. 2002. Engineering a genetic transformation system for Colletotrichum acutatum, the causal fungus of lime anthracnose and postbloom fruit drop. FEMS (Fed. Eur. Microbiol. Soc.) Microbiol. Lett. 213:33-39.

Daub, M. E., and Ehrenshaft, M. 2000. The photoactivated Cercospora toxin cercosporin: Contributions to plant disease and fundamental biology. Annu. Rev. Phytopathol. 38:461-490.

Daub, M. E., Herrero, S., and Chung, K.-R. 2005. Photoactivated perylenequinone toxins in fungal pathogenesis of plants. FEMS (Fed. Eur. Microbiol. Soc.) Microbiol. Lett. 252:197-206.

Davis, V. M., and Stack, M. E. 1991. Mutagenicity of stemphyltoxin III, a metabolite of Alternaria alternata. Appl. Environ. Microbiol. 57:180182.

Espeso, E. A., Tilburn, J., SaÂnchez-Pulido, L., Brown, C. V., Valencia, A., Arst, H. N., Jr., and Peñalva, M. Á. 1997. Specific DNA recognition by the Aspergillus nidulans three zinc finger transcription factor PacC. J. Mol. Biol. 274:466-480.

Fries, N. 1978. Basidiospore germination in some mycorrhiza-forming Hymenomycetes. Trans. British Mycol. Soc. 70:319-324.

Gasteiger, E., Gattiker, A., Hoogland, C., Ivanyi, I., Appel, R. D., and Bairoch, A. 2003. ExPASy: the proteomics server for in-depth protein knowledge and analysis. Nucl. Acid Res. 31: 3784-3788.

Henikoff, J. G., Greene, E. A., Pietrokovski, S., and Henikoff, S. 2000. Increased coverage of protein families with the blocks database servers. Nucleic Acids Res. 28:228-230.

Hudson, J. B., and Towers, G. H. N. 1991. Therapeutic potential of plant photosensitizers. Pharmacol. Ther. 49:181-222.

Jenns, A. E., Daub, M. E., and Upchurch, R. G. 1989. Regulation of cercosporin accumulation in culture by medium and temperature manipulation. Phytopathology 79:213-219.

Keller, N. P., Turner, G., and Bennett, J. W. 2005. Fungal secondary metabolism-from biochemistry to genomics. Nat. Rev. Microbiol. 3:937947.

Kroken, S., Glass, N. L., Taylor, J. W., Yoder, O. C., and Turgeon, B. G. 2003. Phylogenomic analysis of type I polyketide synthase genes in pathogenic and saprobic ascomycetes. Proc. Natl. Acad. Sci. U.S.A. 100:15670-15675.

Liao, H.-L., and Chung, K.-R. 2008. Cellular toxicity of elsinochrome phytotoxins produced by the pathogenic fungus, Elsinoë fawcettii causing citrus scab. New Phytol. 117:239-250

Linden, H., and Macino, G. 1997. White collar-2, a partner in blue light signal transduction, controlling expression of light-regulated genes in Neurospora crassa. EMBO (Eur. Mol. Biol. Organ.) J. 16:98-107.

Liu, W. Z., Shen, Y. X., Liu, X. F., Chen, Y. T., and Xie, J. L. 2001. A new perylenequinone from Hypomyces sp. Chin. Chem. Lett. 12:431-432.

Lousberg, R. J. J. C., Salemink, C. A., Weiss, U., and Batterham, T. J. 1969. Pigments of Elsinö̈ species II. Structure of elsinochromes A, B. and C. J. Chem. Soc. (C):1219-1227.

Lu, S., Lyngholm, L., Yang, G., Bronson, C., Yoder, O. C., and Turgeon, B. G. 1994. Tagged mutations at the Tox1 locus of Cochliobolus heterostrophus by restriction enzyme-mediated integration. Proc. Natl. Acad. Sci. U.S.A. 91:12649-12653.

Marzluf, G. A. 1997. Genetic regulation of nitrogen metabolism in the fungi. Microbiol. Mol. Biol. Rev. 61:17-32.

Pall, M. L., and Brunelli, J. P. 1993. A series of six compact fungal transformation vectors containing polylinkers with multiple unique restriction sites. Fungal Genet. Newslett. 40:59-62.

Ramji, D. P., and Foka, P. 2002. CCAAT/enhancer-binding proteins: Structure, function and regulation. Biochem. J. 365:561-575.

Rangan, V. S., Oskouian, B., and Smith, S. 1996. Identification of an inverted ccaat box motif in the fatty-acid synthase gene as an essential element for mediation of transcriptional regulation by cAMP. J. Biol Chem. 271: 2307-2312.

Saitou, N., and Nei, M. 1987. The neighbor-joining method: A new method for reconstructing phylogenetic trees. Mol. Biol. Evol. 4:406-425.

Shim, W.-B., and Dunkle, L. D. 2003. CZK3, a MAP kinase kinase kinase homolog in Cercospora zeae-maydis, regulates cercosporin biosynthesis, fungal development, and pathogenesis. Mol. Plant-Microbe Interact. $16: 760-768$. 
Shim, W.-B., and Woloshuk, C. P. 2001. Regulation of fumonisin B 1 biosynthesis and conidiation in Fusarium verticillioides by a cyclin-like (C-type) gene, FCC1. Appl. Environ. Microbiol. 67:1607-1612.

Shirasugi, N, and Misaki, A. 1992. Isolation, characterization, and antitumor activities of the cell wall polysaccharides from Elsinoë leucospila. Biosci. Biotechnol. Biochem. 56:29-33.

Stack, M. E., Mazzola, E. P., Page, S. W., Pohland, A. E., Highet, R. S., Tempesta, M. S., and Corely, D. G. 1986. Mutagenic perylenequinone metabolites of Alternaria alternata: Altertoxins I, II, and III. J. Nat. Prod. 49:866-871.

Tabuchi, H., Tajimi, A., and Ichihara, A. 1994. Phytotoxic metabolites isolated from Scolicotrichum graminis Fuckel. Biosci. Biotechnol. Biochem. 58:1956-1959.

Timmer, L. W., Priest, M., Broadbent, P., and Tan, M. K. 1996. Morphological and pathological characterization of species of Elsinö̈ causing scab disease of citrus. Phytopathology 86:1032-1038.

Tsitsigiannis, D. I., and Keller, N. P. 2006. Oxylipins act as determinants of natural product biosynthesis and seed colonization in Aspergillus nidulans. Mol. Microbiol. 59:882-892.

Upchurch, R. G., Walker, D. C., Rollins, J. A., Ehrenshaft, M., and Daub, M. E. 1991. Mutants of Cercospora kikuchii altered in cercosporin synthesis and pathogenicity. Appl. Environ. Microbiol. 57:2940-2945. van Helden, J. 2003. Regulatory sequence analysis tools. Nucleic Acids Res. 31:3593-3596.

Watanabe, A., and Ebizuka, Y. 2004. Unprecedented metabolism of chain length determination in fungal aromatic polyketide synthases. Chem. Biol. 11:1101-1106.

Weiss, U., Ziffer, H., Batterham, T. J., Blumer, M., Hackeng, W. H. L., Copier, H., and Salemink, C. A. 1965. Pigments of Elsinö̈ species I. Pigment production by Elsinö̈ species: Isolation of pure elsinochromes A, B, and C. Can. J. Microbiol. 11:57-66.

Weiss, U., Merlini, L., and Nasini, G. 1987. Naturally occurring perylenequinones. In: Progress in the Chemistry of Organic Natural Products. W. Herz, H. Grisebach, G. W. Kirby, and C. Tamm, eds. Springer-Verlag, New York.

Wu, H., Lao, X. F., Wang, Q. W., and Lu, R. R. 1989. The shiraiachromes: Novel fungal perylenequinone pigments from Shiraia bambusicola. J. Nat. Prod. 5:948-951.

You, B. J., Choquer, M., and Chung, K.-R. 2007. The Colletotrichum acutatum gene encoding a putative $\mathrm{pH}$-responsive transcription regulator is a key virulence determinant during fungal pathogenesis on citrus. Mol. Plant-Microbe Interact. 20:1149-1160.

Yu, J.-H., and Keller, N. 2005. Regulation of secondary metabolism in filamentous fungi. Annu. Rev. Phytopathol. 43:437-458. 